\title{
TWO CASES OF MENINGITIS DUE TO ERYSIPELOTHRIX MONOCYTOGENES
}

\author{
BY \\ HÉLĖNE J. MAIR, N. S. MAIR, E. M. STIRK, and A. W. REID \\ From the Public Health Laboratory Service, Isolation Hospital, Leicester, and the Royal Infirmary, Leicester
}

(RECEIVED FOR PUBLICATION SEPTEMBER 8, 1956)

Meningitis due to Erysipelothrix monocytogenes (Listeria monocytogenes, Pirie) is generally considered to be a rare disease. Kaplan (1945), who reviewed the literature, collected records of 14 proved cases of meningitis due to this organism. Since then at least 14 others have been described, chiefly in the American literature. Murray (1955) believes, however, that human infection with Ery. monocytogenes is probably more common than is realized. He points out that German papers alone list some 150 described cases of meningitis and meningo-encephalitis, granulomatosis infantiseptica, septicaemia, and mononucleosis caused by this organism. Murray estimates that meningitis and meningo-encephalitis comprise roughly $33 \%$ of all published cases.

In this country only two cases of meningitis have been reported. Gibson (1935) described a fatal case in a 37-year-old labourer caused by a diphtheroid organism that was later identified by Webb and Barber (1937) as Listerella monocytogenes. In 1938 Wright and Macgregor (1939) cultivated the organism from the cerebrospinal fluid of a 17-month-old boy dying on the seventh day of illness. The purpose of this paper is to report two apparently unconnected cases of meningitis due to Ery. monocytogenes occurring in Leicestershire within the space of eight weeks, and to focus attention on the existence of a disease that may be more common in this country than the literature indicates.

\section{Case Records}

Case 1.-A man, aged 63, was admitted to the Leicester Isolation Hospital on November 12, 1955, with a severe progressive frontal headache of 12 hours' duration. He had pain at the back of the neck and his legs were stiff, with sciatic pain on flexion. There was no vomiting and no history of head injury. There was nothing relevant in the past medical history.

On examination his temperature was $102.6^{\circ} \mathrm{F}$., pulse rate 68 , and respirations 24 a minute. He had photophobia and was rational though drowsy. There was stiffness of the neck, and Kernig's and Brudzinski's signs were positive. The pupils were equal and reacted normally. The optic fundi were normal. His blood pressure was $130 / 65 \mathrm{~mm}$. Hg.

Lumbar puncture on admission produced a turbid cerebrospinal fluid (C.S.F.) under increased pressure, containing protein, $400 \mathrm{mg}$. per $100 \mathrm{ml}$., sugar, $52 \mathrm{mg}$. per $100 \mathrm{ml}$., and more than 2,000 leucocytes per c.mm. (neutrophils $80 \%$, lymphocytes $20 \%$ ). Gram-positive cocco-bacilli were seen in smears, and culture of the C.S.F. yielded a heavy growth of small transparent colonies on blood agar after 18 hours' incubation (Strain 1).

A blood count on admission showed 10,000 leucocytes per c.mm. (neutrophils $88 \%$, lymphocytes $12 \%$ ) and $\mathrm{Hb} 13.9 \mathrm{~g}$. per $100 \mathrm{ml}$.

Treatment consisted of soluble penicillin, 1 mega unit intramuscularly, and sulphamezathine, $2 \mathrm{~g}$., and chloramphenicol, $500 \mathrm{mg}$., orally every six hours. Penicillin was discontinued after seven days, and sulphamezathine and chloramphenicol after 10 days. Intrathecal soluble penicillin, 15,000 units daily, was also given for the first two days.

The patient's temperature fell to normal 72 hours after admission. Lumbar puncture on November 15 produced a slightly opalescent fluid under normal pressure. There was a decrease in the number of leucocytes (neutrophils $90 \%$, lymphocytes $10 \%$ ). No organisms were seen in smears and culture was sterile. Headache and drowsiness continued, but with diminishing severity, for six days. During this time the general clinical condition slowly improved, but neck stiffness did not disappear until the sixth day after admission. A blood count on November 21 showed 5,500 leucocytes per c.mm. (neutrophils $56 \%$, lymphocytes $38 \%$, monocytes $4 \%$, and eosinophils $2 \%$ ) and $\mathrm{Hb} 14.8 \mathrm{~g}$. per $100 \mathrm{ml}$. A final lumbar puncture on November 22 produced a clear fluid under normal pressure containing protein, $180 \mathrm{mg}$. per $100 \mathrm{ml}$., sugar, $74 \mathrm{mg}$. per $100 \mathrm{ml}$., chlorides, $600 \mathrm{mg}$. per $100 \mathrm{ml}$., and 42 cells per c.mm. (neutrophils $10 \%$, lymphocytes $90 \%$ ). The Paul-Bunnell test on a sample of blood taken on the same day, the eleventh day of illness, was negative. Treatment was stopped on November 22 and the patient was discharged well on November 28 .

Case 2.-A man, aged 40 , was admitted to the Leicester Royal Infirmary on January 8, 1956, with 
violent frontal and retro-orbital headache which had begun two days previously. Twenty-four hours before admission, double vision, photophobia, and some deafness were noticed. There had been no vomiting. There was nothing relevant in the past medical history.

On examination his temperature was $102^{\circ} \mathrm{F}$., pulse rate 90 , and respiration 22 a minute. He was ill, restless, obviously disturbed by severe headache and had photophobia. He was conscious and well orientated, but drowsy. There was stiffness of the neck, pain on turning the head to either side, and a positive Kernig's sign. The pupils were equal with normal reflexes. There was complete paralysis of the left external rectus and weakness of the left side of the face. There was deafness in the right ear and moderate deafness in the left ear. There was no evidence of otitis media. No other cranial nerve lesions were noted. The tendon reflexes were all present and equal, and the plantar responses were flexor. There was a palpable speen. His blood pressure was $160 / 90$ $\mathrm{mm}$. Hg.

Lumbar puncture on admission revealed a turbid fluid under increased pressure containing protein, $180 \mathrm{mg}$. per $100 \mathrm{ml}$., sugar, $14 \mathrm{mg}$. per $100 \mathrm{ml}$., and 800 leucocytes per c.mm. (neutrophils $95 \%$, lymphocytes $5 \%$ ). No organisms were seen in smears. Culture of the C.S.F. produced no apparent growth on overnight incubation, but when the blood agar plates were re-examined after 36 hours there were several small, semi-opaque colonies of Gram-positive cocco-bacilli (Strain 2).

A blood count on January 8 showed 10,300 leucocytes per c.mm. (neutrophils $72 \%$, eosinophils $1 \%$, lymphocytes $19 \%$, and monocytes $8 \%$ ) and $\mathrm{Hb}, 10 \mathrm{~g}$. per $100 \mathrm{ml}$.

A blood culture taken on January 8 was sterile after 10 days' incubation.

The patient was given soluble penicillin, 1 mega unit intramuscularly every four hours for four days, an initial dose of streptomycin, $1 \mathrm{~g}$. intramuscularly, followed by $1 / 3 \mathrm{~g}$. intramuscularly four-hourly for four days, and soluble penicillin, 20,000 units plus streptomycin $100 \mathrm{mg}$. intrathecally once daily, for three days. After the first four days the combined penicillin-streptomycin therapy was stopped and chloramphenicol was given orally, $500 \mathrm{mg}$. six-hourly for 11 days.

The response to treatment was rather slow. The fever was continuous, but with a gradual fall for the first five days, during which time headache and neck stiffness were severe, and there was occasional delirium. The C.S.F., which became sterile after the first day, remained under increased pressure until January 13. A blood count on the same day showed 9,600 leucocytes per c.mm. (neutrophils $80 \%$, lymphocytes $12 \%$, monocytes $8 \%$ ) and $\mathrm{Hb}$ $11.6 \mathrm{~g}$. per $100 \mathrm{ml}$. Thereafter, although the temperature remained at about $99^{\circ} \mathrm{F}$. there was gradual improve ment with diminishing neck s tiffness and drowsiness. Headache persisted until Ja nuary 18 when a lumbar puncture produced a fluid containing protein $400 \mathrm{mg}$. per $100 \mathrm{ml}$., sugar $115 \mathrm{mg}$. per $100 \mathrm{ml}$, and 180 leucocytes per c.mm. (neutrophils $60 \%$, lymphocytes $40 \%$ ). Bilateral facial weakness and nystagmus on both sides appeared on January 18 and were still present when the patient was discharged to the convalescent home on January 30 . The deafness, however, was improved. The left sixth nerve paralysis was still present on discharge. A blood count on January 29 showed 8,200 leucocytes per c.mm. (neutrophils $86 \%$, eosinophils $1 \%$, lymphocytes $12 \%$, monocytes $1 \%$ ) with $\mathrm{Hb} 10.8 \mathrm{~g}$. per $100 \mathrm{ml}$.

\section{Bacteriology}

Morphology.-The organism as seen in the smears from the C.S.F. of Case 1 appeared as a small Grampositive cocco-bacillus occurring singly and in pairs end-to-end, and was at first mistaken for a pneumococcus. In stained preparations from blood agar cultures both strains appeared as small, straight, or slightly curved, Gram-positive rods arranged singly and in pairs. Granules and swollen forms were not seen. There was no evidence of branching. Spores $\underset{-}{\longrightarrow}$ were not formed. Both strains were non-motile at $37^{\circ} \mathrm{C}$., but when grown in broth at room temperature they showed characteristic tumbling motility. Polar $\frac{5}{\infty}$ flagella were demonstrated with difficulty using Kilpatrick's method (Fig. 1).

Cultural Characteristics. - Both strains grew readily on the usual media, producing on blood agar, after 24 hours' incubation at $37^{\circ} \mathrm{C}$., small, circular, domed transparent colonies with a smooth, shining surface and entire edge. On ageing the colonies had $\frac{\mathrm{\Phi}}{\mathbb{}}$ a tendency to become opaque and the edge fimbriate. On primary culture both strains were non-haemo- $\overline{\overline{0}}$ lytic, but after two or three subcultures definite $\frac{3}{\sqrt{3}}$ zones of $\beta$-haemolysis appeared round the colonies. $\frac{\vec{\sigma}}{\sigma}$ Both strains have since remained haemolytic. Growth occurred on MacConkey's medium after $\overline{0}$ 48 hours at $37^{\circ} \mathrm{C}$. and after four days at room tem- perature. On Hoyle's tellurite medium small, black, smooth, circular colonies were visible after 48 hours 8 at $37^{\circ}$ C. Gelatin stab cultures produced filiform $₹$ growth with no liquefaction. In digest broth both 음 strains produced a uniform turbidity with a slight deposit which disintegrated on shaking. Growth을. occurred at $4^{\circ} \mathrm{C}$. and in broth containing $10 \% \mathrm{NaCl} . \tilde{N}$

Biochemical Characteristics. -The biochemical ${ }^{\circ}$ characters of both strains were identical. Acid but no gas was produced in glucose, salicin, laevulose, $\omega$ dextrin, and rhamnose after overnight incubation, in maltose after two days, in sucrose after five days,, and in lactose after eight days. Mannitol, dulcitol,, $\bar{\infty}$ xylose, galactose, and inulin were not fermented: after 28 days. The methyl red test was positive and $\frac{0}{0}$ the Voges-Proskauer reaction weakly positive. $\frac{\text { () }}{\mathbb{P}}$ Indole was not formed. There was no production $\frac{\widehat{D}}{\Phi}$ of $\mathrm{H}_{2} \mathrm{~S}$. Nitrates were not reduced to nitrites in $\mathrm{Q}$ seven days. Both strains were catalase positive. 


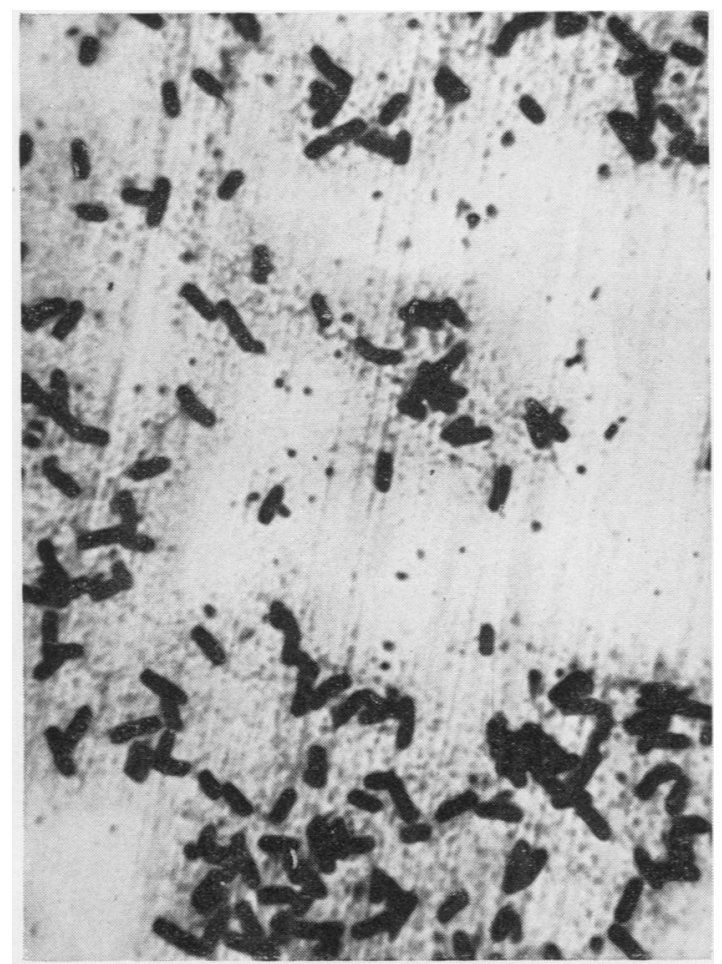

FIG. 1

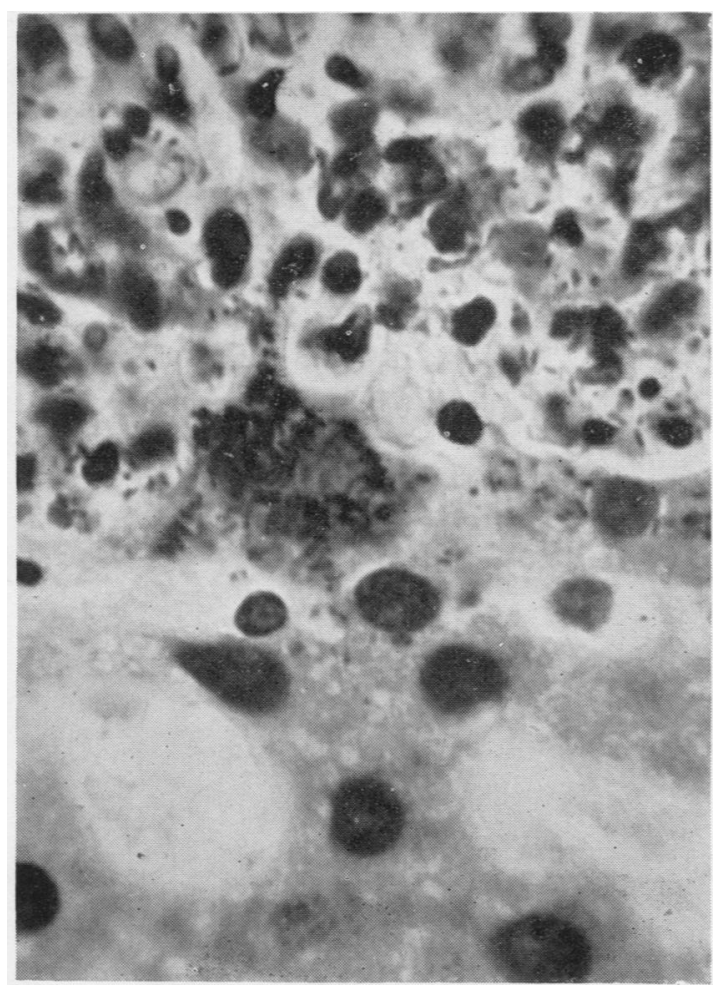

Fig. 3

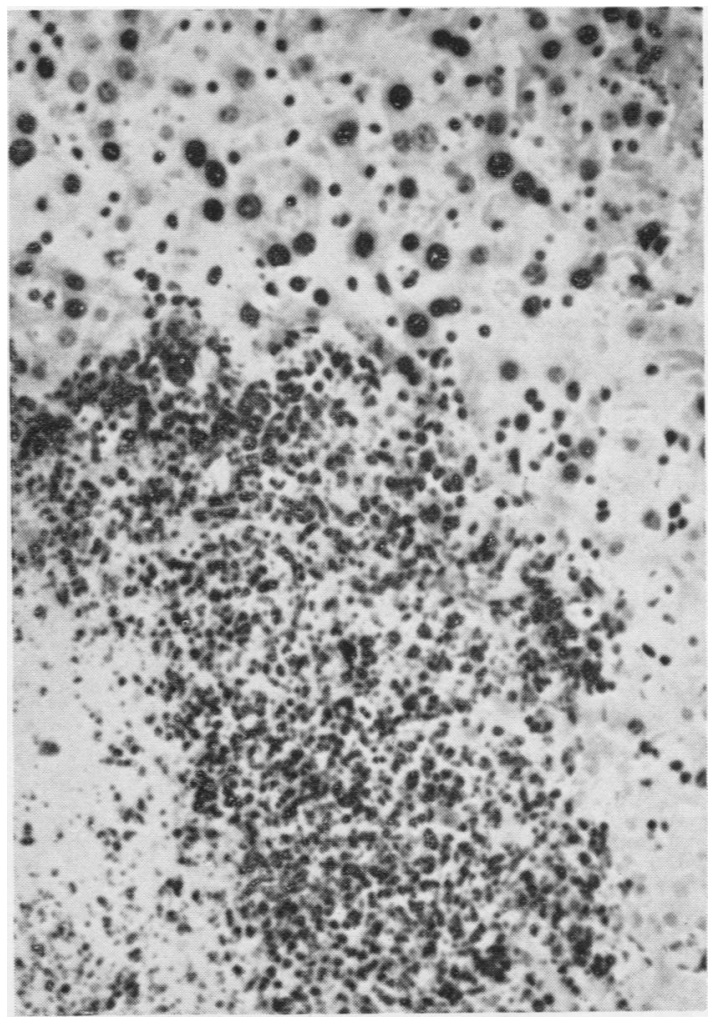

FrG. 2

Fig. 1.-Smear showing polar flagella of Ery. monocytogenes. Kilpatrick's stain, $\times \mathbf{7 2 0}$.

FIG. 2.-Lesion in mouse liver showing area of necrosis, inflammatory exudate, and infiltration of hepatic cells with polymorphs and monocytes. Haematoxylin and eosin, $\times 300$.

FIG. 3.-Mouse liver showing Ery. monocytogenes in large numbers in the inflammatory exudate. Gram's stain, $\times 1,150$. 
Haemolysin Production.-Neither strain showed evidence of soluble haemolysins for horse or sheep red blood cells.

Agglutination and Agglutinin Absorption Tests.Specific antisera were prepared in rabbits against both strains, and against a type specific strain of Ery. monocytogenes No. 7974 obtained from the National Collection of Type Cultures. The results of cross-agglutination tests are shown in Table I, in which the titre of each serum for its homologous strain as well as for the heterologous strains is recorded. Readings were made after four hours in a $53^{\circ} \mathrm{C}$. water-bath, and again after standing overnight at room temperature. No change in end-point was detected at the second reading. Two strains of Ery. rhusiopathiae did not agglutinate with any of the specific antisera.

TABLE I

RESULTS OF AGGLUTINATION TESTS

\begin{tabular}{c|c|c|c}
\hline \multirow{2}{*}{ Antiserum } & \multicolumn{3}{|c}{ Antigen } \\
\cline { 2 - 4 } & Strain 1 & Strain 2 & 7974 (N.C.T.C.) \\
\hline Strain 1 & 10,000 & 10,000 & 10,000 \\
$=, \quad 2$ & 10,000 & 10,000 & 10,000 \\
,,$\quad 7974$ & 5,000 & 5,000 & 5,000 \\
\hline
\end{tabular}

Absorption of agglutinins was carried out for each strain. The absorpiion experiments, as is shown in Table II, indicate that, while strain 1 and type specific strain 7974 are antigenically similar, strain 2 shows some antigenic difference.

TABLE II

RESULTS OF ABSORPTION EXPERIMENTS

\begin{tabular}{|c|c|c|c|c|}
\hline \multirow[b]{2}{*}{ Antiserum } & \multirow{2}{*}{$\begin{array}{c}\text { Atsorbing } \\
\text { Antigen }\end{array}$} & \multicolumn{3}{|c|}{ Agglutinable Antigen } \\
\hline & & Strain 1 & S:rain 2 & $\begin{array}{c}7974 \\
\text { (N.C.T.C.) }\end{array}$ \\
\hline $\begin{array}{cr}\text { Strain } & 1 \\
. . & 1 \\
., & 1 \\
, & 2 \\
. & 2 \\
. & 2 \\
. & 7974 \\
. & 7974 \\
. . & 7974\end{array}$ & $\begin{array}{cr}\text { Strain } & 1 \\
, . & 2 \\
. . & 7974 \\
. . & 1 \\
. . & 2 \\
, . & 7974 \\
, . & 7974 \\
. . & 1 \\
, . & 2\end{array}$ & $\begin{array}{r}0 \\
1,000 \\
0 \\
0 \\
0 \\
0 \\
0 \\
0 \\
1,000\end{array}$ & $\begin{array}{l}0 \\
0 \\
0 \\
0 \\
0 \\
0 \\
0 \\
0 \\
0\end{array}$ & $\begin{array}{r}0 \\
1,000 \\
0 \\
0 \\
0 \\
0 \\
0 \\
0 \\
1,000\end{array}$ \\
\hline
\end{tabular}

Pathogenicity.-A rabbit inoculated with approximately 90 million organisms of strain 2 died overnight with confirmed septicaemia. A similar dose of strain 1 gave rise to a prolonged illness followed by recovery. Instillation of pure suspensions of the strains into the conjunctivae of rabbits produced a severe conjunctivitis within 36 hours.

Intraperitoneal inoculation of white mice gave varied results. Mice which received approximately

\section{E. M. STIRK, and A. W. REID}

9 million organisms were not affected. When the $\overrightarrow{\vec{F}}$ inoculum was increased ten-fold death occurred in from 24 hours to six days. The organism was readily recovered from the heart blood, spleen, and liver. $\frac{\bar{D}}{\bar{D}}$ Several mice which survived for more than two or $\overline{\mathbb{D}}$ three days showed at necropsy multiple focal $\stackrel{\varrho}{\otimes}$ necroses of the liver. On histological section these ${ }^{\infty}$ lesions were surrounded by a rim of neutrophils and $\vec{\circ}$ monocytes with numerous intra- and extra-cellular $\overrightarrow{\vec{\omega}}$ Gram-positive cocco-bacilli (Figs. 2 and 3).

Production of Monocytosis.- -Both strains pro- $\frac{\overline{8}}{0}$ duced a circulating monocytosis in rabbits. Intra- $\vec{\circ}$ venous inoculation of strain 1 produced a mono- $\dot{\omega}$ cytosis rising from $6 \%$ (pre-injection count) to $30 \%$ i in four days. With strain 2 the monocyte count rose from $6 \%$ to $22 \%$ in five days.

Antibiotic Sensitivity.--The strains were tested by $\vec{\nabla}$ the serial-dilution method and were found to be resistant to sulphamezathine ( $>20 \mathrm{mg}$. per $\mathrm{ml}$.) and $\frac{c}{\omega}$ sensitive to penicillin $(0.2$ unit per $\mathrm{ml}$.), chloram- $\stackrel{+}{+}$ phenicol $(5 \mu \mathrm{g}$. per ml.), chlortetracycline $(0.4 \mu \mathrm{g}$. \& per ml.), oxytetracycline $(0.5 \mu \mathrm{g}$. per $\mathrm{ml}$.), and. streptomycin (5 units per $\mathrm{ml}$.).

\section{Discussion}

Ery. monocytogenes was first isolated in July, 융 1924, by Murray, Webb, and Swann (1926) from a $\stackrel{2}{\overrightarrow{7}}$ rabbit and guinea-pig epizootic in Cambridge. In $\frac{3}{3}$ August, 1925, Pirie (1927) in South Africa culti- $\frac{3}{2}$ vated a similar organism from a plague-like disease of gerbilles. Since then Ery. monocytogenes has been isolated from 27 animal species and its presence $\frac{0}{0}$ has been recorded in 26 countries. It is the cause of a specific infectious and often fatal disease in sheep, $\stackrel{3}{3}$. cattle, rabbits, guinea-pigs, and chickens. It has $\mathcal{O}$ also been isolated from the canary, fox, pig, goat, chinchilla, racoon, lemming, ferret, vole, and rat. 옹 In ruminants the disease is characterized by encepha- $\rightarrow$ litis, and in rodents and chickens by septicaemia.

Although the organism appears to be of world- $N$ wide distribution and enzootic in the United States, England, New Zealand, and Germany, relatively few $\mathcal{N}$ cases of human infection have been recorded. The $\underset{\omega}{N}$ part played by animals as a reservoir of infection for $\bar{\sigma}$ human beings has not been determined. With theoc exception of the placenta and vagina as probable $\Phi$ routes of infection in the newborn, little is known of the mode of transmission in man.

As in previously recorded cases, we were unable $\frac{\overrightarrow{0}}{\mathbb{D}}$

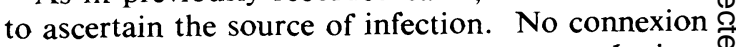
could be found between the two cases, and, since $\stackrel{\mathbb{Q}}{\square}$ the strains showed some antigenic difference, it is 
unlikely that they had a common source. Case 1 , who worked as a packer for a pharmaceutical firm in Loughborough, stated that although he had bred rabbits 20 years previously he could not recall having had any contact with pets or domestic animals within the few months preceding his illness. He admitted, however, that there were one or two mole runs in his garden, and that on November 5 , five or six days before the onset of his illness, he had been examining with his fingers the ramifications of a hole made by a mole. It was not possible to obtain any moles from the patient's garden, but one of us (N. S. M.) examined 50 moles from different paris of the county without finding any evidence of infection. Case 2, an engineer, lived in lodgings in Leicester and had not bcen out of the city for one month before his illness. His landlady's grandson had bought a golden hamster at Christmas from a pet shop. The animal was kept at home, partly in the front room and partly in a shed in the garden, where it died early in January. The hamster was put in a sealed container and buried in the garden. Although the patient had never personally fed or handled it, the animal was exhumed on January 15 and dissected with negative results. There was no evidence of rodents in the house or at his place of work, and he had no known contact with other birds or animals.
Both cases presented with classical signs of meningitis. The intensity and duraiion of the headache (six days in Case 1 and 10 days in Case 2) were striking features, and together with the drowsiness give a picture of an illness which was pursuing a slightly different course from the usual case of bacterial meningitis under treatment.

\section{Summary}

Two cases of meningitis due to Ery. monocytogenes, affecting adult males and occurring in Leicestershire within the space of eight weeks, are described.

Both cases recovered after treatment with penicillin, streptomycin, chloramphenicol, and sulphamezathine.

The bacteriological findings are described.

We wish to thank Dr. J. C. H. Mackenzie, medical superintendent, Leicester Isolation Hospital, and Dr. J. P. W. Jamie, Leicester Royal Infirmary, for permission to publish these cases, and Dr. V. W. Pugh for the early bacteriological findings in Case 2.

\section{REFERENCES}

Gibson, H. J. (1935). J. Path. Bact., 41, 239.

Kaplan, M. M. (1945). New Engl. J. Med., 232, 755.

Murray, E. G. D. (1955). Canad. med. Ass. J., 72, 99.

Webb, R. A., and Swann, M. B. R. (1926). J. Path. Bact., 29, 407. Pirie, J. H. H. (1927). Publ. S. Afr. Inst. med. Res., 3, 163.

Webb, R. A., and Barber, M. (1937). J. Path. Bact. 45, 523.

Wright, H. A., and Macgregor, A. R. (1939). Ibid., 48, 470. 